(RESEARCH ARTICLE)

\title{
Identification and prevalence of intestinal parasites from slaughtered cows in Saki and Ago-Are Abattoirs
}

Adeoti Olatunde Micheal 1, 2, 5, ${ }^{\text {, }}$ Ajayi. Folakemi 1, Olaoye Opeyemi Joy ${ }^{1}$, Adedokun Elisabeth Olajumoke 1, Adesina David Ademola ${ }^{1}$ and Adeoye Kafilat Adenike ${ }^{1,3}$

${ }^{1}$ Department of Science Laboratory Technology, Microbiology Option, The Oke-Ogun Polytechnic Saki, Oyo State Nigeria.

2 Department of Pure \& Applied Biology, Microbiology Option P.M.B. 4000, Ladoke Akintola University of Technology,

Ogbomosho, Oyo State.

${ }^{3}$ Department of Zoology, Parasitology Unit. University of Ibadan, Ibadan Nigeria.

${ }^{4}$ Department of Microbiology \& Botany, University of Ibadan, Nigeria.

${ }^{5}$ Cellular Parasitology Unit, Department of Zoology, University of Ibadan, Nigeria.

Publication history: Received on 21 April 2020; revised on 04 May 2020; accepted on 09 May 2020

Article DOI: https://doi.org/10.30574/wjarr.2020.6.2.0117

\begin{abstract}
Taxonomy is the scientific practice of identifying different organisms, classifying them into categories (taxa) and naming them. A cross-sectional systematic random sampling of 101 cattle slaughtered in major Abattoirs of Saki and Ago -Are were undertaken for six months. The samples were collected and processed by using simple flotation technique. The fecal sample (5g) was collected into a sterile polythene bag and transported to the laboratory for microscopic examination. One gram of fecal sample were dissolved in $20 \%$ Sodium Chloride solution in a universal bottle and centrifuge at $1000 \mathrm{rpm}$ for 3 minutes. A wet preparation of the supernatant was put on a grease-free microscopic glass slide and observed under the microscope. The species of parasite were morphologically correlated with published works online by using Google search engine. The result was statistically analyzed using chi-square at significant difference of $\mathrm{P} \geq 0.05$. The study showed that Oesophagomum (19.8\%), Paramphistomum (5.94\%), Bourgelatia (4.95\%), Eimeria (2.97\%), Trypanosoma spp (6.93\%), Fasciola gigantica (9.90\%), Fasciola hepatica (5.94\%), Schistosoma spp (14.85\%), Tetrahymena (6.93\%) and Trichonympha (2.97\%). In conclusion, male cow were more likely to be infected with gastrointestinal parasites than the female cows. Grazing fields should be kept free from contamination with fecal of cows.
\end{abstract}

Keywords: Prevalence; Gastrointestinal helminths; Parasites; Taxonomy; Helminthiasis

\section{Introduction}

A taxonomy is a field of science (and major component of systematics) that encompasses description, identification, nomenclature, and classification [1] of organism. The "definition" of a taxon is encapsulated by its description or its diagnosis or by both combined. There are no set rules governing the definition of taxa, but the naming and publication of new taxa is governed by sets of rules $[2,3]$. In evolutionary biology, parasitism is a relationship between species, where one organism, the parasite, lives on or in another organism, the host, causing it some harm, and is adapted structurally to this way of life [2]. The entomologist has characterized parasites as "predators that eat prey in units of less than one" [4] Parasites include protozoans such as the agents of malaria, sleeping sickness, and amoebic dysentery; animals such as hookworms, lice, mosquitoes, and vampire bats; fungi such as honey fungus and the agents of ringworm; and plants such as mistletoe, dodder, and the broomrapes. Cattle, the most prominent domesticated livestock in Nigeria, represent some valuable asset in both traditional and modern agriculture. In addition, it also provide meat, milk, skin and draught power for farming [5]. The quantity of meat and revenue obtained from domestic livestock is far below the

\footnotetext{
* Corresponding author: Adeoti Olatunde Micheal
} 
nation demand due to factors such as death and ill heath with associated reduced productivity and increase cost of treatment $[6,7]$.

Farming generates employments and creates markets for larger number of people who explore the animal's products and by products for economic gain [8]. Gastrointestinal parasites (helminthes) cause a major public health problem for farmers in many rural communities including the study area. Adult worm produce eggs that are passed to field in the feces or stool. Under favorable conditions the egg will hatch and larva transmitted to intermediate host snails infect many cattle as well as man [9]. Helminthosis in large part is caused by nematodes, cestodes and trematodes in domestic animals. Helminthosis lead to a reduction in fertility, reduction in food intake, weight loss and milk production increased mortality rate. Gastro intestinal nematode are cosmopolitan parasites that develop within the digestive tract of domestic nematode. The gastrointestinal tract (GIT) of cattle harbors a variety of parasites, particularly helminthes, which cause clinical and sub clinical parasitism. These parasites adversely affect the health status of animals and cause enormous economic losses of the livestock industry $[10,11]$. The effects of infection by gastrointestinal parasites varies according to the parasite concern the degree of infestation and other risk factors such as species, age, season and intensity of worm burden [12].

\section{Material and methods}

\subsection{Study Area}

Saki: is a border town in Oyo State Nigeria bounded by Kwara State in the North and to the West by Cotonou (Republic of Benin) and Lome (Togo). It comprises of three Local Government Area; viz: Saki West, Saki East and ATISBO (AgoAre, Tede, Irawo, Sabe, Baasi and Oje-owode).

\subsection{Demographic Description}

Saki has a population of 178,677 making it the 3rd biggest city in Oyo. It operates on the WAT time zone, which means that it follows the same time zone as Ibadan. It is situated at elevation 472 meters above sea level.

Ago-Are: Ago Are is located in Nigeria. It is positioned in "Africa/Lagos" time zone (GMT+1) with current time of 02:50 PM, Tuesday (difference from your time zone: 99 hours). Ago Are is populated place in Oyo in ATISBO local government area with population of 13.9 thousands.

\subsection{Sample Collection}

Advocacy visits were paid to the abattoirs during pilot study on each day of the sample collection. The study period was between August and October as early as 6:00 am when the animals are usually taken to the abattoir. Healthily animals were identified and labelled as male and female. A total of 101 samples of fresh fecal samples (directly from the rectum of slaughtered cattle, two samples per animal) were collected into clean labeled sterile vials or sample bottles and subsequently taken to the laboratory for microscopic examination.

\subsubsection{Laboratory Preparation}

One gram of fecal sample was dissolved into $20 \%$ solution of sodium chloride (floatation technique) in a universal bottle and centrifuge at 1000 revolution per minutes (1000rpm) for 3 minutes According to [13]. The supernatant was collected in a container and pick on a microscopic glass slide covering with cover slip. The slides were examined microscopically, using digital microscope.

\subsubsection{Examination of Samples}

The slides containing the fecal sample were examined under the microscope using 40x objectives lens for estimation of parasite according to the protocols earlier described by [14]. All structures seen under the microscope were compared with the standard retrieved online thereby the identification of the parasites.

\subsubsection{Statistical Analysis}

Data were subjected to descriptive statistical analysis using percentages in determining the prevalence rate base on the sex. Prevalence of parasite in relation to sex was analyzed using chi-square statistical test (test for significance at $\mathrm{p}>$ $0.05 \%)$. 


\section{Results}

Table 1 Prevalence of Gastrointestinal Parasites in Slaughtered Cows

\begin{tabular}{llll}
\hline Parasites & Sample Examined & Number of positive sample & Prevalence (\%) \\
\hline Bourgelatia diducta & 101 & 5 & 4.95 \\
Elimeria macusaniensis & 101 & 7 & 6.93 \\
Trypanosome spp & 101 & 1 & 0.99 \\
Elimeria spp & 101 & 3 & 2.97 \\
Fasciola gigantica & 101 & 10 & 9.90 \\
Fasciola hepatica & 101 & 6 & 5.94 \\
Flagellate protozoan & 101 & 10 & 9.90 \\
Oesophagostomum bam & 101 & 20 & 19.80 \\
Opalinidea spp & 101 & 6 & 5.94 \\
Opisthorchiasis spp & 101 & 6 & 5.94 \\
Paramphistomum spp & 101 & 6 & 5.94 \\
Schistosoma bovis & 101 & 15 & 14.85 \\
Tetrahymena vorax & 101 & 7 & 6.93 \\
Trichonympha spp & 101 & 3 & 2.97 \\
\hline
\end{tabular}

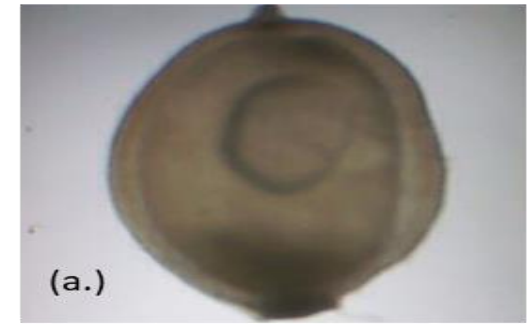

Oesophagostomum bam

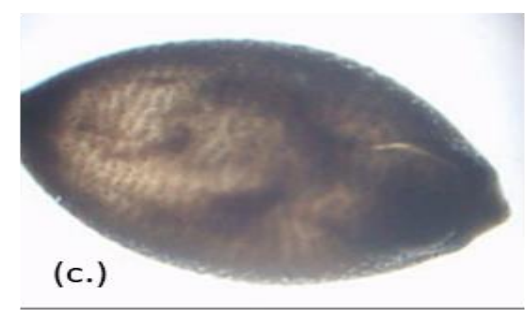

Schistosoma bovis

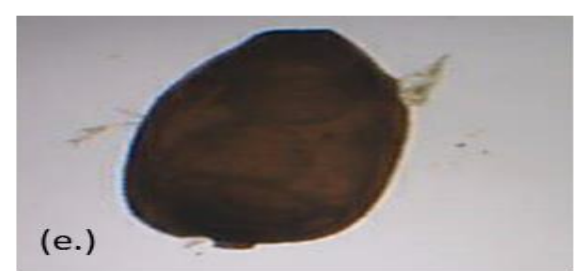

Fasciola gigantica

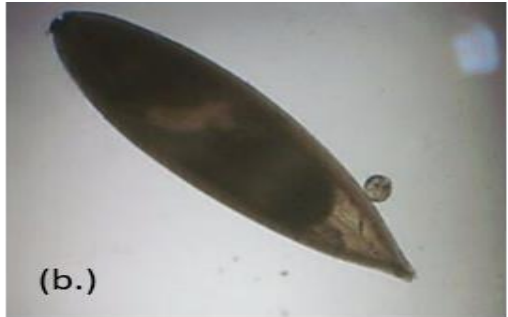

Paramphistomum spp

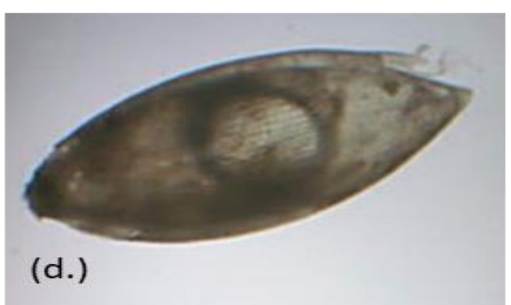

Fasciola hepatica

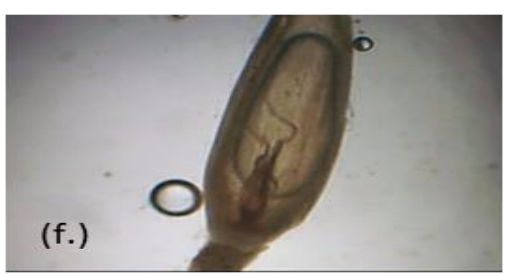

Bourgelatia diducta

Figure 1 Gastrointestinal Parasites in Slaughtered Cows 
Table 2 Descriptive Statistics

\begin{tabular}{llllll}
\hline & N & Mean & Std. Deviation & Minimum & Maximum \\
\hline Male Cattle & 7 & 1.57 & .535 & 1 & 2 \\
Female Cattle & 7 & .14 & .378 & 0 & 1 \\
\hline
\end{tabular}

Table 3 Male Cattle

\begin{tabular}{llll}
\hline & Observed N & Expected N & Residual \\
\hline 1 & 3 & 3.5 & -.5 \\
2 & 4 & 3.5 & .5 \\
Total & 7 & & \\
\hline
\end{tabular}

Table 4 Female Cattle

\begin{tabular}{llll}
\hline & Observed N & Expected N & Residual \\
\hline 0 & 6 & 3.5 & 2.5 \\
1 & 1 & 3.5 & -2.5 \\
Total & 7 & & \\
\hline
\end{tabular}

Table 5 Statistical Test

\begin{tabular}{lll}
\hline & Male Cattle & Female Cattle \\
\hline Chi-Square & $.143 \mathrm{a}$ & $3.571 \mathrm{a}$ \\
Df & 1 & 1 \\
Asymp. Sig. & .705 & .059 \\
\hline
\end{tabular}

$\mathrm{A}=2$ cells $(100.0 \%)$ have expected frequencies less than 5 .

The minimum expected cell frequency is 3.5 table 5 above,

\subsection{For Male Cattle in Ago-are}

Since Asymptomatic Significance $=0.705$ is greater than the P-value (0.05) then the Parasites has significant impact on Male cattle in Ago-are at 5\% significance level.

\subsection{For Female Cattle in Ago-are}

Since Asymptomatic. Significance $=0.059$ is greater than the P-value $(0.05)$ then the Parasites has significant impact on female cattle in Ago-are at 5\% significance level.

Table 6 Saki Chi-Square Analysis Outputs Chi-Square Test

\begin{tabular}{llllll}
\hline & N & Mean & Std. Deviation & Minimum & Maximum \\
\hline Male Cattle & 13 & 1.31 & 1.932 & 0 & 5 \\
Female Cattle & 13 & 6.08 & 4.443 & 0 & 15 \\
\hline
\end{tabular}


Table 7 Male Cattle

\begin{tabular}{llll}
\hline & Observed N & Expected N & Residual \\
\hline 0 & 8 & 2.6 & 5.4 \\
1 & 1 & 2.6 & -1.6 \\
3 & 1 & 2.6 & -1.6 \\
4 & 2 & 2.6 & -.6 \\
5 & 1 & 2.6 & -1.6 \\
Total & 13 & & \\
\hline
\end{tabular}

Table 8 Female Cattle

\begin{tabular}{llll}
\hline & Observed N & Expected N & Residual \\
\hline 0 & 2 & 1.4 & .6 \\
3 & 1 & 1.4 & -.4 \\
4 & 2 & 1.4 & .6 \\
5 & 1 & 1.4 & -.4 \\
6 & 3 & 1.4 & 1.6 \\
7 & 1 & 1.4 & -.4 \\
10 & 1 & 1.4 & -.4 \\
13 & 1 & 1.4 & -.4 \\
15 & 1 & 1.4 & -.4 \\
Total & 13 & & \\
\hline
\end{tabular}

Table 9 Statistical Test

\begin{tabular}{lll}
\hline & Male Cattle & Female Cattle \\
\hline Chi-Square & $14.308 \mathrm{a}$ & $2.923 \mathrm{~b}$ \\
Df & 4 & 8 \\
Asymp. Sig. & .006 & .939 \\
\hline
\end{tabular}

Since Asymptomatic Significance $=0.006$ is less than the P-value $(0.05)$ then the Parasites does not have significant impact on Male cattle in Saki at 5\% significance level. Since Asymptomatic Significance $=0.939$ is greater than the Pvalue (0.05) then the Parasites has significant impact on female cattle in Saki at 5\% significance level.

\section{Discussion}

The findings of this study showed that 95.5\% (96/101) of the cattle screened had parasite infection, thus providing valuable information on the burden of parasite among cattle in Saki, Oyo State. Animals slaughtered in this abattoir are representatives of cattle in the region. Precisely, trematodes such as Fasciola gigantica, Fasciola hepatica, Paramphistomum spp, Schistosoma bovis and Opisthorchaisis was as high as (42.6\%) compared to the result obtained by [15] whose result revealed low infection by trematodes (26.5\%). Fasciola gigantica are liver trematodes known to be zoonotic and have caused considerable economic losses and health problems [16]. Also the high trematodes in this study was in disagreement with the results observed by [16] this might be because they require intermediate hosts to complete their life cycle and so transmission is dependent on the availability of intermediate host Hymnaea spp (snail). This study was in agreement with previous studies conducted in India, Ethiopia and Eastern Nigeria showing that trematodes as the most prevalent helminthes. The present of high trematode in this study compared to the result of [15, 
16] which could be attributed to the differences either in geographical or climatic conditions and ecology since the presence of trematode infections is known to be dependent on availability of the intermediate hosts. Also, this study observed certain prevalence of Tetrahymena spp, Trichonympha spp, Opalinidaes spp, and Trypanonsoma spp. The result of this present study clearly indicates that cattle slaughtered in Saki and its environs of about 450,000 population is served by this abattoir where this study was carried out were infected with a wide variety of gastrointestinal parasite including nematodes, trematodes protozoan and coccidian from the month of August to October. During this rain season, the higher prevalence observed could be attributed to the high moisture content and lower temperature which favor the growth and development of larvae on pasture, in turns favour, contact between the host and parasites. Higher parasitic infection during raining season was reported by some studies [17].

\section{Conclusion}

Various gastrointestinal parasites has been implicated in cattle in Saki compared to Ago-Are due to the cross-migration in the study population. Epidemiological facts suggests that high standard of scriptorium in moder0n animal husbandry will prevent exposure of livestock to graze in deteriorated and polluted land which will be effective in controlling epidemics. Animal should be restricted to special area of land provided by the government for grazing. The public should be enlightened on proper cooking of animal parts especially the intestine and the abattoir workers should be properly trained on meet handling and zoonotic infections. A comprehensive approach should be adopted to ensure all-inclusive meat inspection in the abattoirs before distribution to the public for consumption.

\section{Compliance with ethical standards}

\section{Acknowledgments}

The Author hereby appreciate the abattoirs attenders for their cooperation and understanding.

\section{Disclosure of conflict of interest}

All the authors hereby declared that there is no conflict of interest whatsoever.

\section{References}

[1] Eduardo SL. (1982). The taxonomy of the family Paramphistomidae fischoeder 1901 with reference to the morphology of species occurring in ruminants II. Revision of the genus Paramphistomidae fischoeder 1901. Systematic Parasitology, 4(3), 189-238.

[2] Adedipe OD, Chibuke UE, Oluwatoyin AV, Adejoju AO and Babalola SIC. (2014). Gastrointestinal Helminths in Slaughtered Cattle in Ibadan, South-Western Nigeria J. of Vet Med, 6.

[3] Schmidt GD, Roberts LS and Janovy. (2000). Journal of foundation of parasitology. McGrawhill, Boston, Massachusetts. Science, 670.

[4] Wilson and Edward 0. (2014). The Meaning of Human Existence. W. W. Norton \& Company, 112.

[5] Tewe G. (1997). Sustainability and Development: Paradigms from Nigeria's Livestock Industry, of Bovine Tuberculosis in Abattoirs of the Littoral and Western Highland Regions of the Southeast Asian Journal of Tropical Medicine and Public Health. 28 Supplement, 1, 65-72.

[6] Hossian MM, S Paul, MM Rahman, FM A Hossain, MT Hossain and MR Islam. (2011). "Prevalence and economic significance of caprine fascioliasis at Sylhet district of Bangladesh", Pakistan Veterinary Journal, 31(2), 113-116.

[7] Ozung PO, Nsa EE, Ebebulem VN and Ubua JA. (2011). The Potential of Small Ruminant Production in Cross River Rain Forest Zone of Nigeria: A Review, Continental Journal of Animal and Veterinary Research, 3(1), 33-37.

[8] Ozung PU Owai and KO Oni. (2012). "An assessment of the prevalence of fascioliasis of P. S. Ekong, R. Juryit, N. M. Dika, P. Nguku, and M. Musenero, "Prevalence and risk factors for zoonotic helminth infection among humans and animals-Jos, Nigeria, 2005-2009," The Pan African Medical Journal, 12(6).

[9] Zuko and A Hodzi ${ }^{\vee C}$. (2011). "A slaughterhouse study on prevalence' of sheep liver helminths in region of Sarajevo," MESO, 13, 102-104. 
[10] Nwigwe J0, Njoku 00, Odikamnoro 00 and Uhuo AC. (2013). Comparative study of intestinal helminths and protozoa of cattle and goats in Abakaliki metropolis of Ebonyi State, Nigeria. Advances in Applied Science Research, 4 (2), 223-227.

[11] Okoli IC, Enyinnia NC, Elijah Ag, Omede AA and Unamba-Opara CL. (2012). Animal reproductive management practices of Fulani pastoralists in the humid rain Forest of Imo State, Nigeria Journal of Animal Science Advances 2(2), 221-225.

[12] Ndukum AA, Kudi CG, Bradley IN, Ane-Anyangwe S, Fon-Tebug F and Tchoumboue J. (2011). Prevalence Neglected Tropical Diseases". cdc.gov.

[13] Winrock K. (1983). International. Sheep and Goals in Developing Countries Their Present and Potential Role. A world Bank Technical Paper, Winrock Int Morrilton, Arkansas, U.S.A 72110-9537.

[14] Khin-Khin L. (2007). Prevalence of Cryptosporidium, Giardia and other gastrointestinal parasites in dairy calves in Mandalay, Myanmar, Chuang Mai university and ree Universitat Berlin.

[15] Olubukola DA, Emmanuel CU, Victor OA Oyediran AA and Simeon IB. (2014). Gastrointestinal Helminth is slaughtered cattle in Ibadan, South Western, Nigeria.

[16] Soulsby EJL and Helminths. (1982). Arthropods and Protozoa of Domesticated Animals, Bailliere Tindall, London, UK.

[17] Ohaeri CC. (2012). The parasitic helminths of cattle slaughtered in abattoir in Umuahia South Local Government Area , Abia State, Nigeria. Journal of Applied Research and Technology, 1, 85-89.

\section{How to cite this article}

Adeoti OM, Ajayi F, Olaoye OJ, Adedokun EO, Adesina DA and Adeoye KA. (2020). Identification and prevalence of intestinal parasites from slaughtered cows in Saki and Ago-Are Abattoirs. World Journal of Advanced Research and Reviews, 6(2), 83-89. 